\title{
Mesoporous silica loaded caffeine inhibits inflammatory markers in lipopolysaccharide-activated rat macrophage cells
}

\author{
Mahesh Babu' ${ }^{1}$, Chinnu Jerard ${ }^{2}$, Bibin Punnoose Michael $^{2}$, Sini Suresh ${ }^{2}$, Rajesh Ramachandran ${ }^{2 *}$ \\ ${ }^{1}$ School of Medical Education, M G University, Kottayam, India. \\ ${ }^{2}$ Molecular Biology and Applied Science, Biogenix Research Center, Thiruvananthapuram, India.
}

\begin{tabular}{l}
\hline ARTICLE INFO \\
\hline Received on: $27 / 07 / 2018$ \\
Accepted on: 13/11/2018 \\
Available online: 30/12/2018 \\
\\
\hline Key words: \\
Caffeine, Cyclooxygenase \\
2, TNF alpha, RAW 264.7, \\
wound healing.
\end{tabular}

ABSTRACT
Inflammation is a localized rejoinder towards cellular injury. Caffeine is reported to possess many beneficial properties
but limited bioavailability and increased metabolic clearance limit its therapeutic applications. Mesoporous silica
nanoparticles (MSN) are used as a carrier for sustained drug release owing to its preferable biocompatibility,
biodegradability, and loading efficiency. The present study addressed the efficiency of MSN as a delivery system
of caffeine to limit inflammation in lipopolysaccharide (LPS) activated macrophage cells. Caffeine-loaded silica
nanoparticles (CSNP) were prepared and high-performance liquid chromatography was performed. Analysis of
cyclooxygenase (COX), lipoxygenase, myeloperoxidase, and inducible nitric oxide synthase enzymes authenticates
a comparable anti-inflammatory activity of CSNP over caffeine on LPS activated RAW 264.7 macrophage cells. In
vitro scratch assay uncovered that CSNP has abridged the wound area radically when compared with caffeine and
LPS treated group (control). From the indirect enzyme-linked immunosorbent assay, CSNP produced merest COX-2
and tumor necrosis factor-alpha (TNF- $\alpha$ ) activity. Reverse transcriptase polymerase chain reaction results confirm a
significant decrease in relative expression of COX-2 and TNF- $\alpha$ messenger ribonucleic acid levels in CSNP groups,
thereby proving CSNP's efficient inhibition in the inflammatory response. The results suggest an increase in anti-
inflammatory activity which can be attributed to the sustained release of caffeine from MSN, prompting therapeutic
significance.

\section{INTRODUCTION}

Inflammation, a localized rejoinder towards cellular wound, is manifested by redness, heat, pain, capillary dilatation, and leukocyte infiltration, and is also obliged as a mechanics initiating the obliteration of pestiferous agents and impaired tissue (Nagarkar and Jagtap, 2017; Ryan and Majno, 1977). Inflammation ranges from acute to chronic inflammation which may evolve to cancer, allergies, asthma, and diabetes (Lawrence and Gilroy, 2006; Straub and Schradin, 2016).

Inflammation advances mainly through the arachidonic acid pathway which is conciliated via the enzyme-mediated action of cyclooxygenase-I (COX-I) or prostaglandin-

"Corresponding Author

Rajesh Ramachandran, Director, Center Molecular Biology and Applied Science, Biogenix Research Center, Thiruvananthapuram, India. E-mail: biogenixresearchcenter@outlook.com endoperoxide synthase (Ricciotti and FitzGerald, 2011; Samuelsson, 1991). Nuclear factor kappa-light-chain-enhancer of activated B cells (NF- $\kappa \mathrm{B})$ is the paramount transcriptional factor in the synchronization of pro-inflammatory genes, such as interleukin-6 (IL-6), nitric oxide, inducible nitric oxide synthase (iNOS), and COX-2 (Dlaska and Weiss, 1999; Hwang et al., 2016). Its activation is widely stigmatized in inflammatory diseases and considerable scrutiny on the advancement of antiinflammatory drugs targeting NF- $\kappa \mathrm{B}$ was reported (Yin et al., 1998). Although several chemical classes of NF- $\kappa B$ inhibitors have been recognized, it is only for a few of those that a safety analysis based on a comprehensive interpretation of their pharmacologic mechanism of action has been recorded (Gupta et al., 2010; Mora et al., 2012). The evolution of tumor necrosis factor-alpha (TNF- $\alpha$ ) inhibitors has, moreover, been one of the most vigorous fields of therapeutics more than a decade for the management of inflammatory diseases (Baugh and Bucala, 2001; Jackson, 2007). 
Inflammatory response preceding tissue injury is quite cardinal in playing a key role both in normal and pathological healing which includes the activation of the innate immune system, enrollment of inflammatory cells to the site of injury etc. (Koh and DiPietro, 2011; Kokkas, 2010). The wound-healing progression involves four vastly incorporated along with superimposing phases, such as hemostasis, inflammation, proliferation, and tissue remodeling or resolution (Broughton et al., 2006; Pugin, 2012). Delayed acute plus chronic injuries immigrate a pathologic inflammation due to partial or uncoordinated healing process (Koh and DiPietro, 2011). Characteristic of both chronic wounds and acute wounds that fail to heal is enormous leukocytosis and abridged matrix deposition (Ashcroft et al., 2003). The factors that impact repair can be assorted into local and systemic (Guo and DiPietro, 2010).

Caffeine, a phytochemical found in coffee plants is recognized to have biological characteristics, such as anti-oxidant, anti-aging, and anti-obesity effects (DaSilva et al., 2017). The wellacknowledged starting place of caffeine is the Coffea Arabica plant seed (Patay et al., 2017). This white crystalline Xanthine alkaloid analeptic drug is observed in the seeds, coffee plant, and the leaves of the tea bush (Ashihara et al., 2017; Hwang et al., 2016). It was revealed to have less IL-6, TNF- $\alpha$ (Horrigan et al., 2006; Popko et al., 2010), cell death, and inflammation, such as COX-2 in caffeine-infused rats than in those who had the placebo (Li et al., 2011). In the last two decennaries, mesoporous silica nanoparticles (MSN) have acquired increased attention for medical applications because of their humongous biocompatibility, biodegradability, storage stability, controllable diameter, maximum drug loading efficiency, and large amendable surface potential (Brezániová et al., 2018). To this regard, caffeine-loaded silica nanoparticles (CSNP) authenticate higher penetration rate when juxtaposed with caffeine.

\section{MATERIALS AND METHODS}

\section{Preparation of CSNP}

The silica nanoparticles were prepared by the method of Stöber et al. (1968) with slight modifications. $1.5 \mathrm{ml}$ tetraethyl orthosilicate $(99 \%), 50 \mathrm{ml}$ ethanol, and $6.25 \mathrm{mg} \cdot \mathrm{ml}^{-1}$ caffeine were blended as well as subjected to heat under a heating mantle until the reaction mixture attained $64^{\circ} \mathrm{C}$, which was then proceeded by adding $2.5 \mathrm{ml}$ liquid ammonia. The reaction mixture was then subjected under magnetic stirrer for 18 hours along with centrifugation at $8,000 \mathrm{rpm}$ for 10 minutes. The pellet thus formed was washed with $70 \%$ ethanol three times and the particle was air dried which was then replaced into a sterile tube and stored at $-4^{\circ} \mathrm{C}$.

\section{High-performance liquid chromatography}

To estimate the encapsulation efficiency of CSNP, highperformance liquid chromatography (HPLC) was performed. The testing was performed by means of Agilent 1260 series of HPLC system (Agilent Technologies, Palo, Alto, CA) with a quaternary pump (Agilent Technologies 1260), a vacuum degasser, changeable wavelength detector, a $20 \mu \mathrm{l}$ sample injector, and a column thermostat. The separation was made on Zorbax Eclipse Plus 18 columns of $5 \mu \mathrm{m}, 200 \mathrm{~mm} \times 4.6 \mathrm{~mm}$. The mobile phase comprised of solvent A (Acetonitrile) and solvent B (Water) in 50:50 proportions at $1 \mathrm{ml}$. minute $^{-1}$ flow rate and the wavelength to be detected was at $271 \mathrm{~nm}$. The column thermostat was maintained at room temperature.

\section{Anti-inflammatory assays}

Lipopolysaccharide (LPS) stimulated RAW 264.7 rat macrophage cell lines exposed with different concentrations (25, 50 , and $100 \mu \mathrm{g} / \mathrm{ml}$ ) of caffeine and CSNP was compared with Diclofenac sodium in concentrations parallel to the sample and kept for 24 hours incubation. After incubation, the lysed cells were used for enzymatic studies.

Assay of $C O X$

The COX action was assayed by Walker and Gierse method (Bindu et al., 2016). The assay mixture contained 100 $\mathrm{mM}$ Tris-hydrochloric acid (Tris-HCl) buffer, $5 \mathrm{mM}$ glutathione, $5 \mu \mathrm{M}$ hemoglobin, and enzyme. The reaction was initiated by arachidonic acid addition and ended after 20 minutes incubation at $37^{\circ} \mathrm{C}$ by means of $0.2 \mathrm{ml}$ of $10 \%$ trichloroacetic acid in $\mathrm{HCl}$ and $0.2 \mathrm{ml}$ of thiobarbituric acid addition. The contents were subjected in a boiling water bath for 20 minutes, cooled, and centrifuged at $1,000 \mathrm{rpm}$ for 3-5 minutes. The supernatant thus obtained was measured for its COX activity at $632 \mathrm{~nm}$ and was demonstrated in terms of percentage COX inhibition.

Assay of 5-lipoxygenase

The assay of 5-lipoxygenase (5-LOX) activity was performed as per Axelrod et al. (1981). The reaction was carried out in a quartz cuvette at $25^{\circ} \mathrm{C}$ with $1 \mathrm{~cm}$ light path. The assay mixture contained $2.75 \mathrm{ml}$ of Tris buffer of $\mathrm{pH} 7.4,0.2 \mathrm{ml}$ of sodium linoleate, and $50 \mu \mathrm{l}$ of the enzyme. The increase in optical density was calculated in $234 \mathrm{~nm}$ and the percentage of inhibition was calculated.

\section{Myeloperoxidase (MPO) activity}

Cell lysate was homogenized in a solution containing $50 \mathrm{mM}$ potassium phosphate buffer and $0.57 \%$ hexadecyltrimethylammonium bromide. Homogenized mixture was frozen in liquid nitrogen and thawed, followed by sample centrifugation at 2,000 rpm for 30 minutes at $4^{\circ} \mathrm{C}$. The supernatant obtained was quantified for myeloperoxidase (MPO) assay. MPO in the sample was activated by addition of $50 \mathrm{mM}$ phosphate buffer of pH 6 containing $1.67 \mathrm{mg} \cdot \mathrm{ml}^{-1}$ Guaiacol and $0.0005 \% \mathrm{H}_{2} \mathrm{O}_{2}$ addition and the absorbance at $450 \mathrm{~nm}$ was measured (Bradley et al., 1982).

iNOS

iNOS was done by the method described by Salter et al. (2002). Cell lysate was diluted to $2 \mathrm{ml}$ of 4-(2-hydroxyethyl)-1piperazineethanesulfonic acid buffer. The assay system contained $0.1 \mathrm{ml} \mathrm{L}$-Arginine, $0.1 \mathrm{ml}$ manganese chloride, $0.1 \mathrm{ml} 30 \mu \mathrm{g}$ dithiothreitol, $0.1 \mathrm{ml}$ nicotinamide adenine dinucleotide phosphate, $0.1 \mathrm{ml}$ tetrahydropterin, $0.1 \mathrm{ml}$ oxygenated hemoglobin, and $0.1 \mathrm{ml}$ cell lysate. The increase in absorbance was recorded at $401 \mathrm{~nm}$.

\section{Scratch wound healing assay}

Exponentially growing L929 fibroblast cell lines were trypsinized and seeded at a density of 200,000 cell for each well 
into 12 well plate for 24 hours incubation ( $90 \%$ Confluence). The scratch wound was done using a sterile $1 \mathrm{ml}$ pipette tip by means of a pre-marked line. The cell monolayer was rinsed three times with phosphate buffered saline (PBS) after removal of the resulting debris from five lineal scratches. It was then followed by incubation with the sample for 24 hours. The wound regions were subjected by taking an image, nearly above the interchanges between scratched wound region and pre-marked lines and the outcome of $25 \mu \mathrm{g}$ sample on wound closure was estimated microscopically ( $4 \times$ magnification, Olympus CKX41). The end result of the caffeine and CSNP on wound closure was determined in terms of the area using Image J-MRI-Image analysis software at 0,24 , and 48 hours (Liang et al., 2007).

\section{COX-2 and TNF- $\alpha$ estimation}

Briefly, cell lysates were coated on 96 well plates and were blocked using blocking buffer containing $0.2 \%$ gelatin in $0.05 \%$ Tween 20 in PBS and kept for 1-hour incubation at room temperature. It was then washed two times with PBS Tween 20 and $100 \mu \mathrm{l}$ of COX-2 and TNF- $\alpha$ antibody (Santa Cruz, USA) was added and then left for 2 hours at room temperature. It was again washed with PBS [two times]. One hundred microliter of horseradish peroxidase (HRP) conjugated (IgE) antibody was then added and left for 1 hour at room temperature (RT). Chromogen, o-Dianisidine containing $1 \mathrm{mg} / 100 \mathrm{ml}$ methanol, $21 \mathrm{ml}$ citrate buffer $\mathrm{pH} 5$, and $60 \mathrm{ml}$ fresh hydrogen peroxide $\left(\mathrm{H}_{2} \mathrm{O}_{2}\right)$ was added and subjected to incubation for 30 minutes at RT. The reaction was terminated by adding $50 \mu \mathrm{l} 5 \mathrm{~N} \mathrm{HCl}$ and the absorbance was read at $415 \mathrm{~nm}$ after 5-30 minutes.

\section{Reverse transcriptase polymerase chain reaction}

Total ribonucleic acid (RNA) was obtained from samples with TRIzol (Invitrogen, USA). The reaction was carried out on ice with an overall volume of $20 \mu$, containing $5 \mu \mathrm{l}$ RNA, $1 \mu \mathrm{l}$ of forward and reverse primers of COX-2 and TNF- $\alpha, 10 \mu \mathrm{l}$ of primer reverse transcriptase polymerase chain reaction (RT-PCR) premix, and $3 \mu$ l nuclease free water. Incubation was done using thermal cycler (Eppendorf Master Cycler) and complementary deoxyribonucleic acid (cDNA) produced was stored at $-20^{\circ} \mathrm{C}$ till the RT-PCR step. The levels of TNF- $\alpha$ and COX-2 were compared to glyceraldehyde 3-phosphate dehydrogenase (GAPDH) RNA in RT-PCR studies and the following cycling conditions were employed for RTPCR: Initial DNA synthesis at $42^{\circ} \mathrm{C}$ for 30 minutes, followed by denaturation at $94^{\circ} \mathrm{C}$ for 10 minutes, denaturation repeated at $94^{\circ} \mathrm{C}$ for 1 minute, annealing at $58^{\circ} \mathrm{C}$ for 1 minute, and extension at $72^{\circ} \mathrm{C}$ for 1 minute which was continual for 35 cycles along with the final extension at $72^{\circ} \mathrm{C}$ for 5 minutes. The following primers (Eurofins Scientific, India) were used (Table 1).

\section{Agarose gel electrophoresis}

The amplified products were run on $1.5 \%$ Agarose gel and viewed using a gel documentation system (E-Gel Imager, Invitrogen, and USA) and the relative band intensity was determined using ImageJ analysis software (Sugden et al., 1975).

\section{Statistical analysis}

The data were represented as Mean \pm standard deviation (SD) $(n=3)$. Statistical significance was determined by one-way analysis of variance (ANOVA) using Graph Pad Prism Software (5.01) and $p<0.05$ was considered significant.

\section{RESULTS}

\section{HPLC}

Caffeine was observed to have a loading efficiency of nearly $28 \%$ which is identified as significant (Fig. 1).

\section{Anti-inflammatory assays}

Assay of $\mathrm{COX}$

COX is involved in prostaglandin synthesis which is responsible for the function of inflammatory signals. From the result, it can be examined that caffeine and CSNP produced a noticeable decrease in COX activity when correlated with LPS treated group. CSNP produced an expressive inhibition when compared with caffeine alone treated group confirming an indicative inhibition of COX activity in CSNP treated groups over caffeine alone treated group (Fig. 2A).
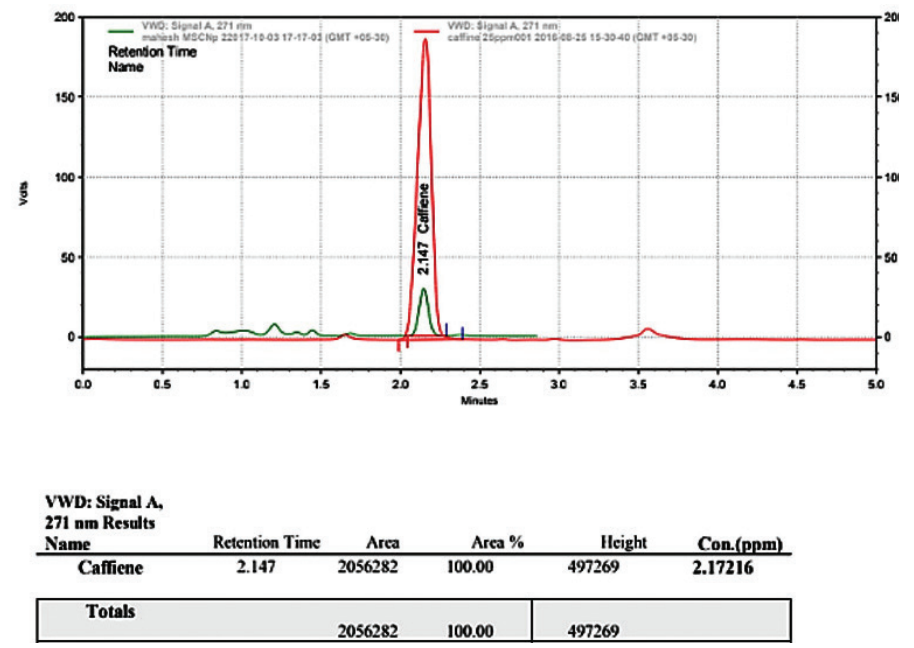

Figure 1. HPLC chromatogram of caffeine-loaded MSN.

Table 1. Primers used for the study.

\begin{tabular}{lll}
\hline \multirow{2}{*}{ oligo name } & Forward & Reverse \\
\cline { 2 - 3 } & Sequence $\left(\mathbf{5}^{\prime}->\mathbf{3}^{\prime}\right)$ & Sequence $\left(\mathbf{5}^{\prime}-\mathbf{> 3}^{\prime}\right)$ \\
\hline GAPDH & GAAGGTGAAGGTCGGAGTC & GAAGATGGTGATGGGATTTC \\
TNF- $\alpha$ & CCCAGGCAGTCAGATCATCTTC & AGCTGCCCCTCAGCTTGA \\
COX-2 & GGAGAGACTATCAAGATAGT & ATGGTCAGTAGACTTTTACA \\
\hline
\end{tabular}




\section{Assay of LOX}

5-LOX, responsible for leukotrienes production, is the major responses for inflammation. The result showed a suggestive decrease in LOX activity of caffeine, as well as CSNP in comparison with the LPS treated group. Clearly, CSNP produced a noticeable inhibition when related to caffeine alone treated group authenticating a sound inhibition of LOX activity in CSNP treated groups over caffeine alone treated group (Fig. 2B).

\section{MPO activity}

It can be scrutinized that caffeine and CSNP produced an observable decrease in MPO activity when correlated with the LPS treated group. As an inference, the result confirms a slight abatement in MPO activity of CSNP treated groups over caffeine alone treated group (Fig. 3).

\section{iNOS}

Excessive nitric oxide production by iNOS in stimulated inflammatory cells is believed to be a contributory factor of cellular injury in inflammation. It can be suggested from the result that caffeine and CSNP produced a significant inhibition of iNOS protein wherein CSNP recognizably expressed a slight more inhibition of iNOS protein than the caffeine alone treated group (Fig. 4).

\section{Scratch wound healing assay}

The wound healing capacity was determined by in vitro scratch assay. It can be observed that caffeine and CSNP have appreciably abridged the wound area when related with the nontreated group. The above results depict that CSNP has decreased the wound area significantly when compared with caffeine and untreated control cells (Fig. 5).

\section{Enzyme-linked immunosorbent assay}

Indirect enzyme-linked immunosorbent assay (ELISA) was performed to measure the amount of protein content of both COX-2 and TNF- $\alpha$ in inflammatory conditions and post-treatment.

\section{ELISA for COX-2}

The COX enzymes catalyze a major step in the conversion of arachidonate to prostaglandin $\mathrm{H} 2$, the instantaneous
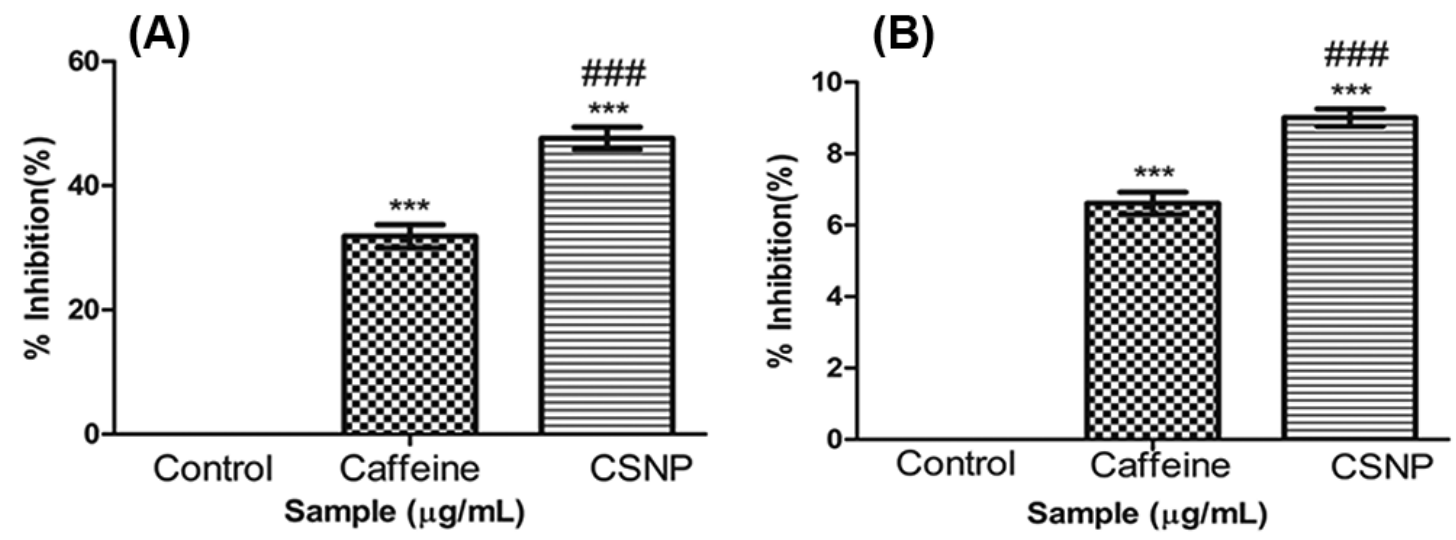

Figure 2. (A) Cyclooxygenase activity. (B) Lipoxygenase activity. Along $Y$ axis-Percentage inhibition of COX activity, Along $X$ axis—Treated groups. One-way ANOVA and Bonferroni's Multiple comparison test were performed to analyze data at each time point. $* * * p<0.001$ compared to LPS treated group, \#\#\#p<0.001 compared to caffeine group. Data represented as Mean \pm SD where $n=3$.

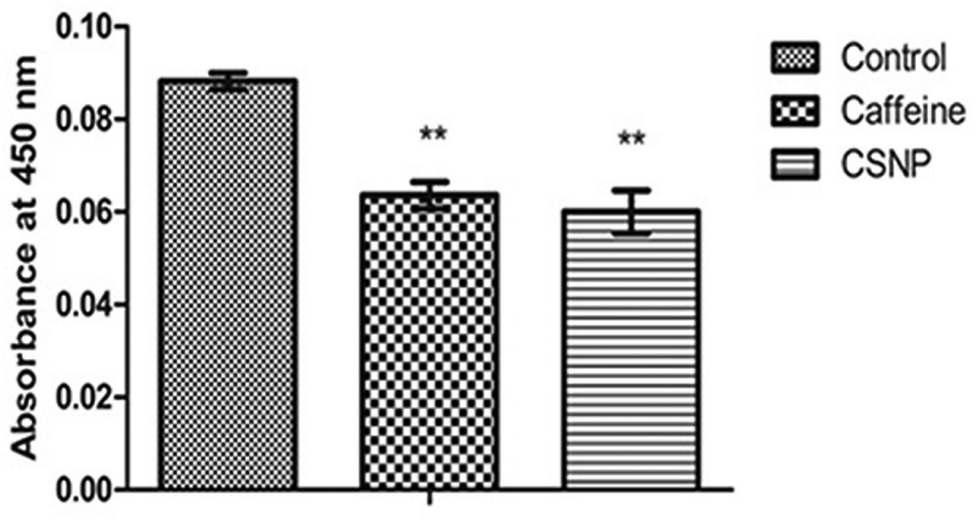

\section{Sample $(\mu \mathrm{g} / \mathrm{mL})$}

Figure 3. MPO activity. Along $Y$ axis_-Absorbance at $450 \mathrm{~nm}$, Along $X$ axis-Treated groups. One-way ANOVA and Bonferroni's multiple comparison test were performed to analyze data at each time point. ${ }^{*} p<0.005$ compared to LPS treated group. Data represented as Mean \pm SD where $n=3$. 


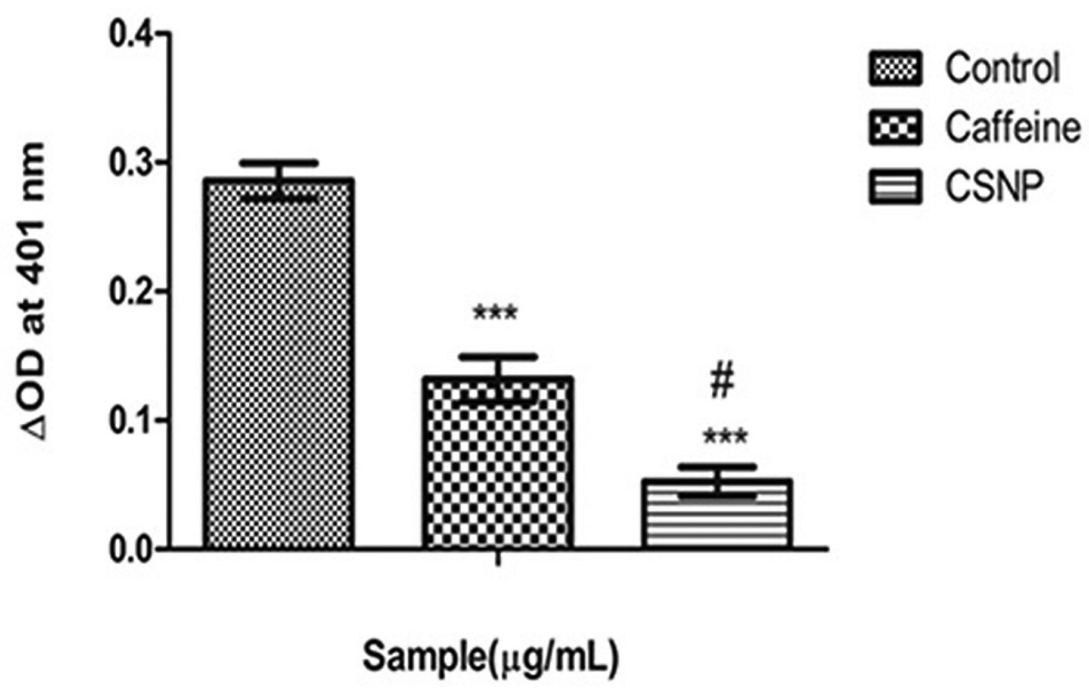

Figure 4. iNOS. Along $Y$ axis—iNOS activity in optical density (OD) units, Along $X$ axis-Treated groups. One-way ANOVA and Bonferroni's multiple comparison test were performed to analyze data at each time point. ${ }^{* *} p<0.001$ compared to LPS treated group, $\# p<0.01$ compared to caffeine group. Data represented as Mean \pm SD where $n=3$.
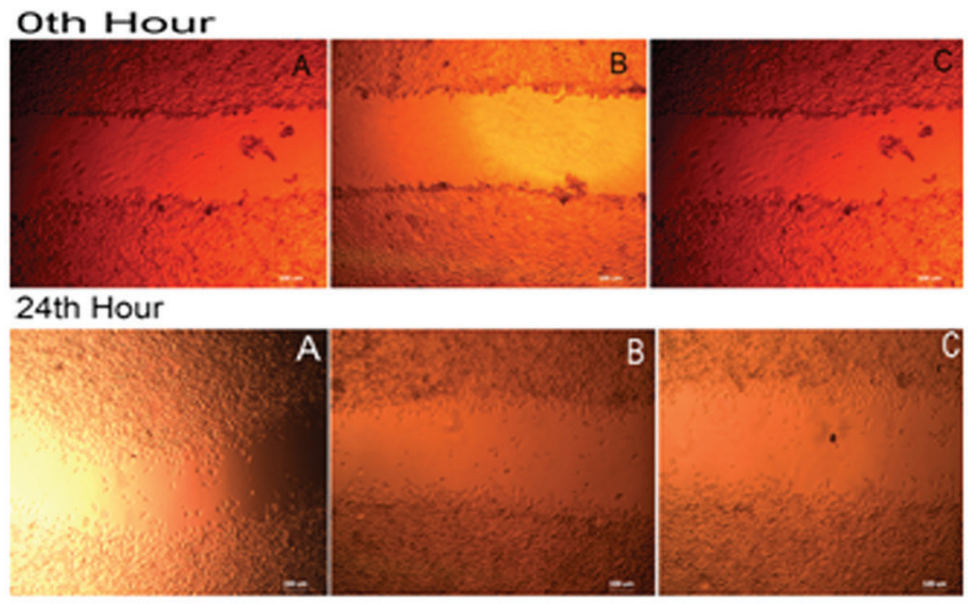

\section{8th Hour}
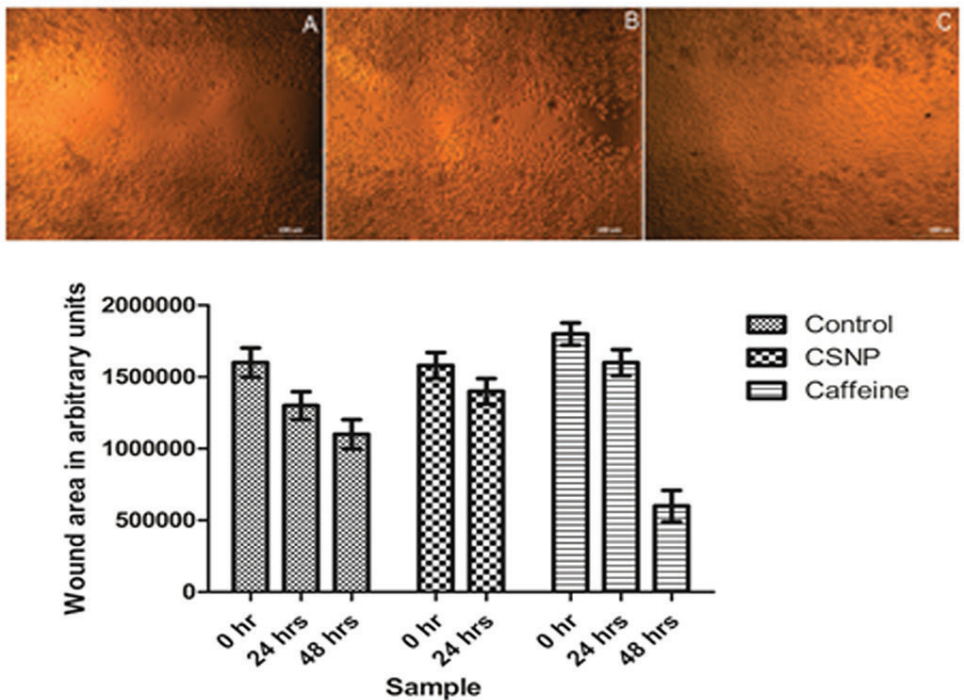

Figure 5. Scratch wound healing assay. Phase contrast images of L929 fibroblast cells subjected to wound (Olympus CKX 41-4× magnification). (A) Control, (B) Caffeine, and (C) Caffeine loaded silica nanoparticle. Graphical representation of scratch wound healing assay measured using ImageJ-MRI Image analysis software Along $Y$ axis-Wound area in arbitrary units, Along $X$ axis-Treated groups at 0th, 24th, and 48th hours. Data represented as Mean \pm SD where $n=3$. 
substrate for a sequence of cell-specific prostaglandin and thromboxane synthase. As of the result, it is spotted that caffeine and CSNP produced less COX-2 activity when juxtaposed with the LPS treated group, where CSNP expressed the least possible COX-2 activity over caffeine alone treated group (Fig. 6A).

\section{ELISA for TNF- $\alpha$}

TNF- $\alpha$ is a central regulator of inflammation. From the result, it can be noticed that caffeine and CSNP produced lesser TNF- $\alpha$ activity in comparison with the LPS treated group. Notably, CSNP exhibited the least TNF- $\alpha$ activity which uncovers the fact that CSNP is more effective than caffeine (Fig. 6B).

\section{mRNA expression of COX-2 and TNF- $\alpha$}

RT-PCR was adopted to determine the relative expression of COX-2 and TNF- $\alpha$ and from the results it is noticeable that CSNP was more efficient in inhibiting COX-2 inflammatory response in correlation with free caffeine in terms of band intensity and there was considerable down-regulation of
TNF- $\alpha$ on CSNP treated cells when correlated with LPS treated group (Fig. 7).

\section{DISCUSSION}

Recent findings attributing therapeutic effects of caffeine to be an anti-inflammatory agent are gaining attention among researchers and addressing the pharmacokinetic and pharmacodynamic constraints, including metabolic clearance along with increased solubility remains the need of the hour. The utility of MSN as a carrier for caffeine in mediating anti-inflammatory activity was evaluated in the present study. The commendatory chemical characteristics, biocompatibility, and safety uphold MSN as a potent drug carrier (Bharti et al., 2015; Vallet-Regi et al., 2017; Watermann and Brieger, 2017). HPLC method was used to determine the loading efficiency of caffeine wherein the results showed a loading efficiency of $10.8 \%$ which is comparatively lesser than reported for mesoporous nanoparticles (Mohseni et al., 2015).

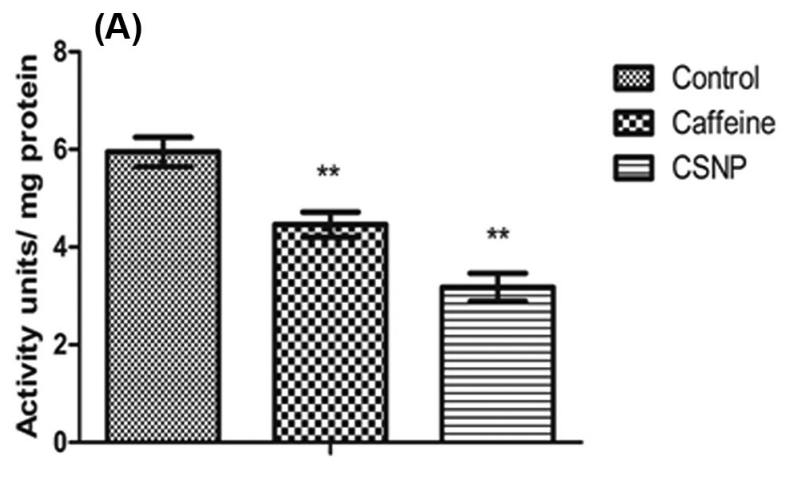

Sample $(\mu \mathrm{g} / \mathrm{mL})$

(B)

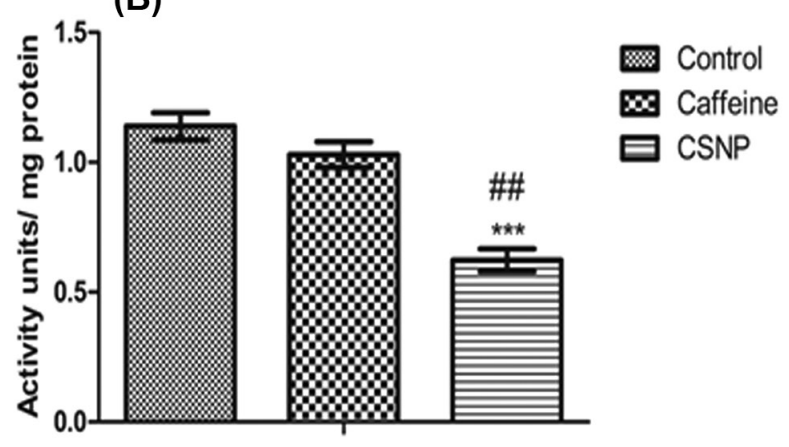

Sample $(\mu \mathrm{g} / \mathrm{mL})$

Figure 6. (A) Cyclooxygenase-2 ELISA estimation. Along $Y$ axisActivity units per milligram protein, Along $X$ axis-Treated groups. Oneway ANOVA and Bonferroni's multiple comparison test were performed to analyze data at each time point. $*^{*} p<0.005$ compared to LPS treated group. Data represented as Mean \pm SD where $n=3$. (B) TNF- $\alpha$ ELISA estimation. Along $Y$ axis-Activity units per milligram protein, Along $X$ axis-Treated groups. One-way ANOVA and Bonferroni's multiple comparison tests were performed to analyze data at each time point. $* * * p<0.001$ compared to LPS treated group, \#\#p<0.005 compared to caffeine group. Data represented as Mean \pm SD where $n=3$.

\section{LPS-activated macrophage cells were exposed to non-
toxic concentrations of caffeine and CSNP showed a significant \\ LPS-activated macrophage cells were exposed to non-
toxic concentrations of caffeine and CSNP showed a significant}
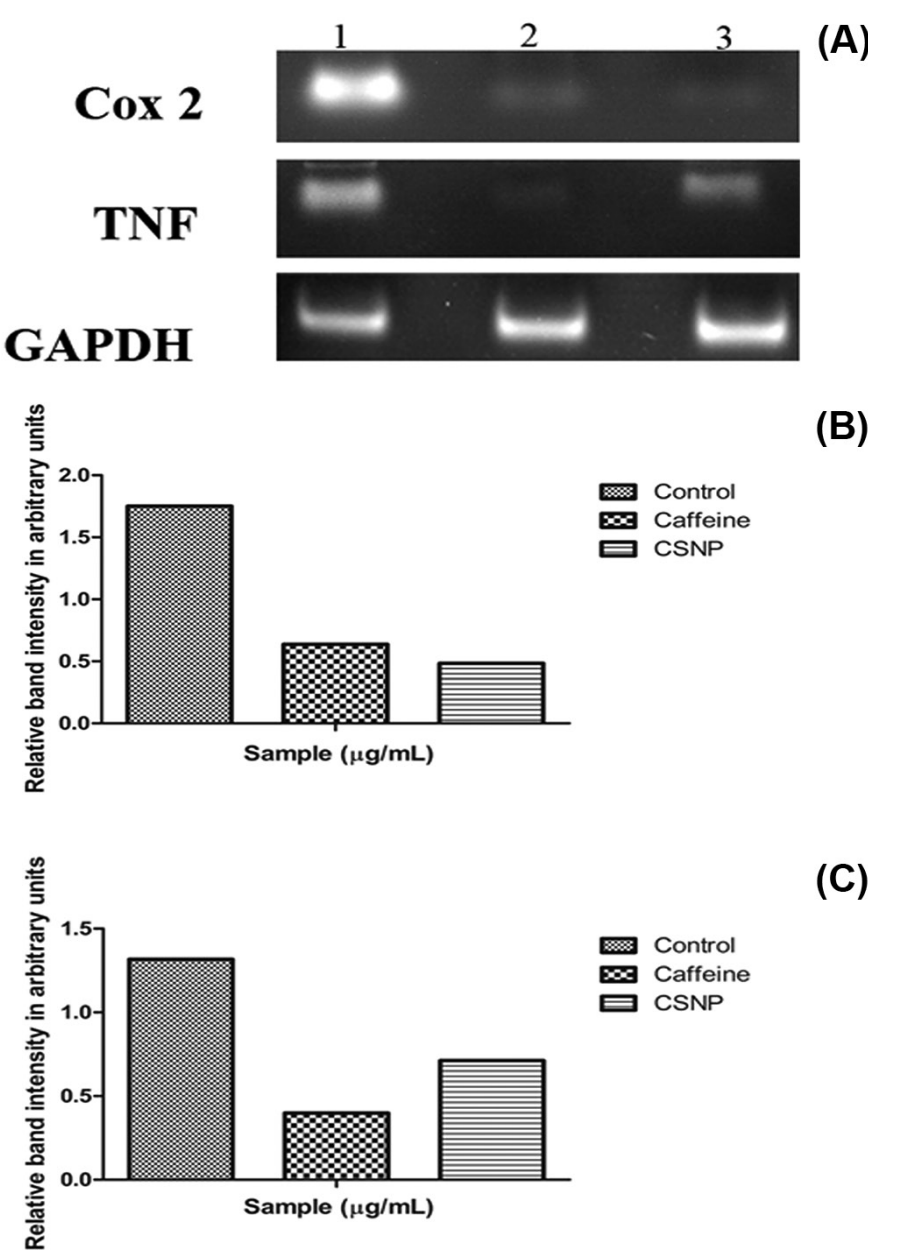

(B)

(C)

Figure 7. (A) mRNA expression of anti-inflammatory markers. (B) Relative band intensity measured by ImageJ analysis software-Along $Y$ axis-relative band intensity of COX-2 expression in arbitrary units, Along $X$ axis-samples. (C) Relative band intensity measured by ImageJ analysis software-Along $Y$ axis - relative band intensity of TNF- $\alpha$ expression in arbitrary units, Along $X$ axis-samples. 
inhibition of COX and LOX activity. The outcome of coffee extracts on inhibiting the inflammatory signals is previously reported by Lee et al. (2013) and Jung et al. (2017), but the antiinflammatory potential of caffeine studies are least reported. From our results, when correlated with free caffeine, CSNP were more effective in ameliorating the inflammatory signals.

In vitro wound healing scratch assay is considered as a potential biomarker to assess migrating potential of cells across a wound has, in turn, became a tool to measure the cytotoxic activity of compounds on dividing cells (Liang et al., 2007). Caffeine was observed to enhance the wound closure in a significant manner along with CSNP. When weighed against with control, the area of the experimental wound was closed in a significant manner by nearly 48 hours incubation. Coffee extracts are already reported to enhance wound healing processes in animal models by subsiding the inflammatory responses and apart from that, the antioxidant activity of caffeine is also well-documented (Affonso et al., 2016; Ojeh et al., 2016; Yashin et al., 2013). Here, also the CSNP is retaining the antioxidant potential to mitigate the cell migration and the study also portrays nontoxicity of MSN towards studied fibroblast cells.

Messenger RNA (mRNA) expression analysis and protein analysis of COX-2 and TNF- $\alpha$ have shown a significant down-regulation and COX-2 inhibitory potential of crude caffeine is reported by Chu et al. (2012) which is in accordance with our findings. The interesting fact that CSNP loading has, in turn, increased the COX inhibitory potential which can be due to the sustained releasing ability of CSNP particles.It can be summarized that the anti-inflammatory potential of caffeine can be exploited to generate a sustained release system to combat inflammation in a safer manner.

\section{CONCLUSION}

Targeting caffeine as a formidable anti-inflammatory agent is limited by bioavailability and solubility. Hence, delivery of caffeine using MSN for prospecting anti-inflammatory activity was considered in LPS activated RAW 264.7 macrophage cells and CSNP effectively alleviated COX and 5-LOX activity along with a concomitant decrease in MPO and iNOS activity. Also, COX-2 and TNF- $\alpha$ expression were reduced by CSNP similarly to free caffeine. Therefore, our results confirm sustained antiinflammatory activity of CSNP which is comparable to free caffeine.

\section{REFERENCES}

Affonso RCL, Voytena APL, Fanan S, Pitz H, Coelho DS, Horstmann AL, Pereira A, Uarrota VG, Hillmann MC, Varela LAC, Ribeirodo-Valle RM, Maraschin M. Phytochemical composition, antioxidant activity, and the effect of the aqueous extract of coffee (Coffeaarabica L.) bean residual press cake on the skin wound healing. Oxid Med Cell Longe, 2016; 1-10; doi:10.1155/2016/1923754

Ashcroft GS, Mills SJ, Lei K, Gibbons L, Jeong M-J, Taniguchi M, Burow M, Horan MA, Wahl SM, Nakayama T. Estrogen modulates cutaneous wound healing by downregulating macrophage migration inhibitory factor. J Clin Invest, 2003; 111:1309-18; doi:10.1172/JCI16288

Ashihara H, Mizuno K, Yokota T, Crozier A. Xanthine alkaloids: occurrence, biosynthesis, and function in plants, in: progress in the chemistry of organic natural products 105 , progress in the chemistry of organic natural products. Springer, Cham, Switzerland, pp 1-88, 2017; doi:10.1007/978-3319-49712-9 1
Axelrod B, Cheesebrough TM, Laakso B. Lipoxygenase from soybeans methods in enzymology. Academic Press, Cambridge, UK, Vol. 71 pp 441-53, 1981.

Baugh JA, Bucala R. Mechanisms for modulating TNF alpha in immune and inflammatory disease. Curr Opin Drug Discov Devel, 2001; $4: 635-50$

Bharti C, Gulati N, Nagaich U, Pal A. Mesoporous silica nanoparticles in target drug delivery system: a review. Int J Pharm Invest, 2015; 5:124; doi:10.4103/2230-973X.160844

Bindu AR, Aleykutty NA, Harindran J. In vitro anti-inflammatory screening of stem bark of CordiaobliquaWilld. in RAW 264.7 cell lines. J Pharm Res, 2016; 10:370-6.

Bradley PP, Priebat DA, Christensen RD, Rothstein G. Measurement of cutaneous inflammation: estimation of neutrophil content with an enzyme marker. J Invest Dermatol, 1982; 78:206-9; doi:10.1111/1523-1747.ep12506462

Brezániová I, Záruba K, Králová J, Sinica A, Adámková H, Ulbrich P, Poučková P, Hrubý M, Štěpánek P, Král V. Silica-based nanoparticles are efficient delivery systems for temoporfin. Photodiagn Photodyn Ther, 2018; 21:275-84; doi:10.1016/j.pdpdt.2017.12.014

Broughton G, Janis JE, Attinger CE. The basic science of wound healing. Plastic Reconstruct Surg, 2006; 117:12S-34S; doi:10.1097/01. prs.0000225430.42531.c2

Chu Y-F, Chen Y, Brown PH, Lyle BJ, Black RM, Cheng IH, Ou B, Prior RL. Bioactivities of crude caffeine: Antioxidant activity, cyclooxygenase-2 inhibition, and enhanced glucose uptake. Food Chem, 2012; 131:564-8; doi:10.1016/j.foodchem.2011.09.024

DaSilva LA, Wouk J, Weber VM, Eltchechem CL, Almeida P, Martins JCL, Malfatti CR, Osiecki R. Mechanisms and biological effects of Caffeine on substrate metabolism homeostasis: a systematic review. J App Pharm Sci, 2017; 7(06):215-21.

Dlaska M, Weiss G. Central role of transcription factor NF-IL6 for cytokine and iron-mediated regulation of murine inducible nitric oxide synthase expression. J Immunol, 1999; 162:6171-7.

Guo S, DiPietro LA. Factors affecting wound healing. J Dent Res, 2010; 89:219-29; doi:10.1177/0022034509359125

Gupta SC, Sundaram C, Reuter S, Aggarwal BB. Inhibiting $\mathrm{NF}-\kappa \mathrm{B}$ activation by small molecules as a therapeutic strategy. Biochim Biophys Acta, 2010; 1799:775-87.

Horrigan L, Kelly J, Connor T. Immunomodulatory effects of caffeine: Friend or foe? Pharmacol Therap, 2006; 111:877-92; doi:10.1016/j. pharmthera.2006.02.002

Hwang J-H, Kim K-J, Ryu S-J, Lee B-Y. Caffeine prevents LPSinduced inflammatory responses in RAW264.7 cells and zebrafish. Chem Biol Interact, 2016; 248:1-7; doi:10.1016/j.cbi.2016.01.020

Jackson JM. TNF- alpha inhibitors. Dermatol Ther, 2007; 20:251-64; doi:10.1111/j.1529-8019.2007.00138.x

Jung S, Kim MH, Park JH, Jeong Y, Ko KS. Cellular antioxidant and anti-inflammatory effects of coffee extracts with different roasting levels. J Med Food, 2017; 20:626-35; doi:10.1089/jmf.2017.3935

Koh TJ, DiPietro LA. Inflammation and wound healing: the role of the macrophage. Expert Rev Mol Med, 2011; 13; doi:10.1017/ S1462399411001943

Kokkas B. Tissue injury and inflammation. Ann Gen Psychiatry, 2010; 9:S1; doi:10.1186/1744-859X-9-S1-S1

Lawrence T, Gilroy DW. Chronic inflammation: a failure of resolution? The resolution of inflammation. Int J Exp Pathol, 2006; 88:8594; doi:10.1111/j.1365-2613.2006.00507.x

Lee K-W, Im J-Y, Woo J-M, Grosso H, Kim Y-S, Cristovao AC, Sonsalla PK, Schuster DS, Jalbut MM, Fernandez JR, Voronkov M, Junn E, Braithwaite SP, Stock JB, Mouradian MM. Neuroprotective and anti-inflammatory properties of a coffee component in the MPTP model of Parkinson's disease. Neurotherapeutics, 2013; 10:143-53; doi:10.1007/ s13311-012-0165-2

Li X-Y, Xu L, Lin G-S, Li X-Y, Jiang X-J, Wang T, Lü J-J, Zeng B. Protective effect of caffeine administration on myocardial 
ischemia/reperfusion injury in rats. Shock, 2011; 36:289-94; doi:10.1097/ SHK.0b013e3182222915

Liang C-C, Park AY, Guan J-L. In vitro scratch assay: a convenient and inexpensive method for analysis of cell migration in vitro. Nat Protocol, 2007; 2:329-33; doi:10.1038/nprot.2007.30

Mohseni M, Gilani K, AlirezaMortazavi S. Preparation and characterization of rifampin loaded mesoporous silica nanoparticles as a potential system for pulmonary drug delivery. Iran J Pharm Res, 2015; $14: 27-34$.

Mora E, Guglielmotti A, Biondi G, Sassone-Corsi P. Bindarit: an anti-inflammatory small molecule that modulates the NFkB pathway. Cell Cycle, 2012; 11:159-69; doi:10.4161/cc.11.1.18559

Nagarkar B, Jagtap S. Effect of new polyherbal formulations DF1911, DF2112 and DF2813 on CFA induced inflammation in rat model. BMC Complement Alternat Med, 2017; 17; doi:10.1186/s12906-017-1711-6

Ojeh N, Stojadinovic O, Pastar I, Sawaya A, Yin N, Tomic-Canic $M$. The effects of caffeine on wound healing: effects of caffeine on wound healing. Int Wound J, 2016; 13:605-13; doi:10.1111/iwj.12327

Patay ÉB, Bencsik T, Papp N. Phytochemical overview and medicinal importance of Coffea species from the past until now. Asian Pac J Trop Med, 2016; 9:1127-35; doi:10.1016/j.apjtm.2016.11.008

Popko K, Gorska E, Stelmaszczyk-Emmel A, Plywaczewski R, Stoklosa A, Gorecka D, Pyrzak B, Demkow U. Proinflammatory cytokines Il- 6 and TNF- $\alpha$ and the development of inflammation in obese subjects. Eur J Med Res, 2010; 2(15 Suppl):120-2.

Pugin J. How tissue injury alarms the immune system and causes a systemic inflammatory response syndrome. Ann Intensive Care, 2012; 2:27; doi:10.1186/2110-5820-2-27

Ricciotti E, FitzGerald GA. Prostaglandins and inflammation. Arterioscler Thromb Vasc Biol, 2011; 31:986-1000; doi:10.1161/ ATVBAHA.110.207449

Ryan GB, Majno G. Acute inflammation. A review. Am J Pathol, $1977 ; 86: 183-276$

Salter M, Duffy C, Garthwaite J, Strijbos PJLM. Ex vivo measurement of brain tissue nitrite and nitrate accurately reflects nitric oxide synthase activity in vivo. J Neurochem, 2002; 66:1683-90; doi:10.1046/ j.1471-4159.1996.66041683.x
Samuelsson B. Arachidonic acid metabolism: role in inflammation. Z Rheumatol, 1991; 50:3-6.

Stöber W, Fink A, Bohn E. Controlled growth of monodisperse silica spheres in the micron size range. J Colloid Interface Sci, 1968; 26:629; doi:10.1016/0021-9797(68)90272-5

Straub RH, Schradin C. Chronic inflammatory systemic diseases. Evol Med Public Health, 2016; 37; doi:10.1093/emph/eow001

Sugden B, DeTroy B, Roberts RJ, Sambrook J. Agarose slab-gel electrophoresis equipment. Anal Biochem, 1975; 68:36-46; doi:10.1016/0003-2697(75)90676-4

Vallet-Regí M, Colilla M, Izquierdo-Barba I, Manzano M. Mesoporous silica nanoparticles for drug delivery: current insights. Molecules, 2017; 23:47; doi:10.3390/molecules23010047

Watermann A, Brieger J. Mesoporous silica nanoparticles as drug delivery vehicles in cancer. Nanomaterials, 2017; 7:189; doi:10.3390/ NANO7070189

Yashin A, Yashin Y, Wang J, Nemzer B. Antioxidant and antiradical activity of coffee. Antioxidants, 2013; 2:230-45; doi:10.3390/ antiox2040230

Yin M-J, Yamamoto Y, Gaynor RB. The anti-inflammatory agents aspirin and salicylate inhibit the activity of IкB kinase- $\beta$. Nature, 1998; 396:77-80; doi:10.1038/23948

\section{How to cite this article:}

Babu M, Jerard C, Michael BP, Suresh S, Ramachandran R. Mesoporous silica loaded caffeine inhibits inflammatory markers in lipopolysaccharide-activated rat macrophage cells. J Appl Pharm Sci, 2018; 8(12): 124-131. 